\title{
LA FÁBULA DE PROMETEO Y PANDORA DE MIGUEL (DANIEL LEVÍ) DE BARRIOS: NOTAS SOBRE LA DIÉGESIS MÍTICA ${ }^{1}$
}

\author{
INMACULADA GARCÍA GAVILÁN \\ Universidad de León
}

\section{INTRODUCCIÓN}

Miguel (Daniel Leví) de Barrios es, sin duda, una de las figuras más emblemáticas, atractivas y silenciadas del Barroco hispánico². Nacido en Montilla en 1635,

\footnotetext{
1 Recibido: 30-XI-2009 Aceptado: 15-II-2010
}

2 Hasta la fecha, la crítica sólo ha explorado poco más de un tercio de la producción literaria global de Miguel de Barrios. Espigamos a continuación los estudios más destacados: K. R. Scholberg, La poesía religiosa de Miguel de Barrios, Universidad de Ohio-Edhigar S. L., Madrid, 1961; Ch. J. Moolick, The Poetic Styles of Miguel de Barrios, Universidad de Carolina de Sur, Los Ángeles, 1964; W. C. Pieterse, Daniel Levi de Barrios als geschiedschrijver van de Portuguees-Israëlietische gemeente te Ámsterdam in zijn «Triumpho del govierno popular», Scheltema \& Holkema NV, Ámsterdam, 1968; J. Rebollo, El teatro alegórico de Miguel (Daniel Leví) de Barrios, Juan de la Cuesta, Newark, Delaware, 1996; H. Den Boer, La literatura sefardí de Ámsterdam, Instituto Internacional de Estudios Sefardíes y Andalusíes, Alcalá de Henares, 1996; Miguel de Barrios, Las Fábulas Mitológicas: Flor de Apolo, F. J. Sedeño (ed.), Universidad de Málaga, (Col. Autores Recuperados, 2), 1996; Miguel de Barrios, Complete Works. I. Obras Dramáticas, M. Lazar y F. J. Pueyo 
pertenece a esa tercera generación de poetas barrocos que -junto a Anastasio Pantaleón de Ribera, Bernardino de Rebolledo o Antonio de Solís- incluye un pequeño grupo de exiliados sefardíes, entre los que destacan, además de nuestro poeta, João Pinto Delgado o Antonio Enríquez Gómez ${ }^{3}$. Desde su obligado destierro en la capital holandesa hasta su muerte en $1701^{4}$, Miguel de Barrios desarrolló una diversa e ingente producción literaria que comprende lírica, prosa y teatro. Confió su desmesurada pluma a muchos de los géneros poéticos practicados en el siglo XVII, como la poesía encomiástica, ecfrástica, pastoril, amorosa, satírico-burlesca o la fábula mitológica. Así lo evidencia la hibridación genérica que caracteriza sus dos poemarios más sugerentes, Flor de Apolo (1665) y Coro de las Musas $(1672)^{5}$, los que revelan, bien avanzado ya el siglo XVII, la pervivencia de la creación miscelánea típica del Seiscientos. Sus obras llevan la impronta del magisterio gongorino y de otros modelos áureos -Quevedo, Lope de Vega o Calderón-, a los que incorpora su particular legado judaico, enriquecido por su vinculación a la comunidad judía de Ámsterdam, conformando así una fructífera simbiosis que confiere a Barrios una originalidad e interés fuera de toda discusión.

Pese a tan excelente carta de presentación, la crítica, amparada durante demasiado tiempo en el epígrafe de «autor menor», apenas si ha pasado de puntillas por la obra del proteico montillano y la de otros escritores que -como él-desarrollaron su producción literaria al abrigo de la nueva poesía instaurada por Góngora, dentro o fuera de nuestras fronteras. La desidia exegética provocó entonces que autores como Anastasio Pantaleón de Ribera, Miguel Colodrero de Villalobos, Bernardino de

(eds.), Labyrinthos, Los Ángeles, 2002 y Miguel de Barrios, Flor de Apolo, F. J. Sedeño (ed.), Reichenberger, Kassel, 2005. Por último, la línea de investigación que estamos desarrollando en torno al montillano ha arrojado algunos resultados, entre los que podemos espigar los siguientes: La poesía amorosa en el Coro de las Musas de Miguel de Barrios, Ayuntamiento de Montilla / Universidad de Córdoba, 2002; «Reflexiones biográfico-literarias sobre un judío montillano del siglo XVII: Miguel (Daniel Leví) de Barrios», en F. M. Espino Jiménez (ed.), Actas de las V Jornadas sobre Historia de Montilla, Ayuntamiento de Montilla, 2003, 165-186; «Tras el hilo de Ariadna: Miguel de Barrios y su recepción crítica en Europa», Ámbitos, 12, 2004, 19-24; «Una aproximación al retrato poético femenino en el Coro de las Musas de Miguel de Barrios», en J. Matas, J. M. Trabado y J. J. Alonso (eds.), La maravilla escrita. Antonio de Torquemada y la literatura del Siglo de Oro, Universidad de León, 2005, 377-388; «Notas sobre lo satírico y lo burlesco en el Coro de las Musas de Miguel de Barrios», Criticón, 100, 2007, pp. 27-40, «¿De qué se ríen los sefardíes de Ámsterdam? Daniel Leví de Barrios y la literatura satírico-burlesca», J. Matas Caballero y J. M. Balcells Doménech (eds.), Cervantes y su tiempo. II., Lectura y signo, Anejo I, pp. 361-370.

3 J. M. Rozas y M. A. Pérez, «Trayectoria de la poesía barroca», en B. W. Wardropper (ed.), Historia y Crítica de la Literatura Española. III. Siglo de Oro: Barroco, Crítica, Barcelona, 1983, 631-668, pág. 638. A propósito de la inclusión de Barrios en esta cronología los autores puntualizan que «(...) Formaría, sin embargo, junto a otros sefarditas coetáneos exiliados, como Antonio Enríquez Gómez o João Pinto Delgado, un grupo aparte dentro de la misma, por compartir una desdibujada geografía vital que los separa de otros miembros de su generación» (págs. 654-655).

4 Los datos relativos a la biografía del poeta, pueden consultarse en mis trabajos, ya citados, «Reflexiones biográfico-literarias sobre un judío montillano del siglo XVII: Miguel (Daniel Leví) de Barrios» y «Miguel de Barrios: Reseña biográfica de un epígono singular», en La poesía amorosa, págs. 13-26.

5 Las citas referidas a ambos poemarios están tomadas de las ediciones siguientes: Flor de Apolo, Baltasar Vivien, Bruselas, 1665 y Coro de las Musas, Baltasar Vivien, Bruselas, 1672. 
Rebolledo, Antonio Enríquez Gómez o el propio Miguel de Barrios fueran relegados al olvido. Por fortuna, el fértil y riguroso proceso de recuperación que estos «olvidados ilustres» vienen experimentando en los últimos años ha legitimado definitivamente su presencia en las coordenadas estéticas del Barroco literario ${ }^{6}$.

El polimorfismo que acusa el legado poético de Daniel Leví de Barrios, carente aún de una revisión crítica global y exhaustiva en muchos de sus aspectos esenciales, nos ofrece una extensa paleta cromática que, si bien nos permite bosquejar el ignoto lienzo de su geografía literaria, también nos impone -por su magnitud- un acto consciente de selección. Por ello, en las páginas siguientes, vamos a recalar en una de las vertientes más atractivas de su obra -la fábula mitológica-, a la que Daniel Leví dedicó un exquisito florilegio de composiciones que lo convierten en uno de los cultivadores más prolíficos del mencionado género. Como pequeño botón de muestra, vamos a centrar nuestra atención en el rarísimo epilio ${ }^{7}$ que el poeta sefardí dedicara al mito prometeico: la Fábula de Prometeo y Pandora ${ }^{8}$.

6 Esta fértil recuperación de los minori, abanderada por el Prof. J. Lara Garrido, está dando frutos excelentes, como se refleja en los trabajos sobre Pantaleón de Ribera y Colodrero de Villalobos realizados por J. Ponce Cárdenas, entre los que destacamos: «La mentira pura de Baco y Erígone: breve nota a un poema burlesco», en J. Huerta, E. Peral y J. Ponce (eds.), Tiempo de burlas. En torno a la literatura burlesca del Siglo de Oro, Verbum, Madrid, 2001, 145-160; A. Pantaleón de Ribera, Obra selecta, J. Ponce Cárdenas (ed.), Universidad de Málaga (Col. Autores Recuperados, 6), 2003, «La poesía de Miguel Colodrero de Villalobos: consideraciones en torno al epilio y los motivos del retiro en la naturaleza», en J. Roses (ed.), Góngora Hoy VI. Góngora y sus contemporáneos: de Cervantes a Quevedo, Diputación de Córdoba (Col. Estudios Gongorinos, 4), 2004, 145-198; «En torno a la dilogía salaz: bifurcaciones eróticas y estrategias burlescas en la poesía de Miguel Colodrero de Villalobos», en J. I. Díez Fernández y A. L. Martín (coords.), Venus venerada: tradiciones eróticas en la literatura española, Editorial Complutense, Madrid, 2006, 107-136; “En torno a algunos sonetos 'ejemplares' de Miguel Colodrero de Villalobos", Península, 3 (2006), pp. 151164; o «De burlas y enfermedades barrocas: la sífilis en la obra poética de Anastasio Pantaleón de Ribera y Miguel Colodrero de Villalobos», Criticón, 100, 2007, pp. 115-42. Para el caso del Conde de Rebolledo, R. González Cañal ha editado con esmero sus Ocios, Servicio de Publicaciones de la Universidad de Castilla-La Mancha, Cuenca, 1997. La obra del sefardí A. Enríquez Gómez ha merecido las sugerentes apreciaciones de J. I. Díez, «La mezcla de géneros en las Academias Morales de las Musas, de A. Enríquez Gómez.1. Los Sonetos», A. Alonso, «La mezcla de géneros en las Academias Morales de las Musas de A. Enríquez Gómez. 2. La tradición pastoril» e I. Colón, «La mezcla de géneros en las Academias Morales de las Musas, de Antonio Enríquez Gómez. 3. Las Elegías», todos ellos incluidos en F. Díaz Esteban (ed.), Los judaizantes en Europa y la literatura castellana del Siglo de Oro, Letrúmero, Madrid, 1994, 131-136, 35-38 y 97-101, respectivamente, así como las de J. Matas, «Un cancionero del exilio en las Academias Morales de las Musas de Antonio Enríquez Gómez», Il confronto letterario, 43, 2005, 51-74.

7 Utilizo el término epilio como sinónimo de fábula mitológica, siguiendo la atinada acepción que a dicha voz concede J. Ponce Cárdenas en su espléndida monografía Góngora y la poesía culta del siglo XVII, Madrid, Laberinto (Arcadia de las Letras, 10), 2001.

8 Al final de estas páginas incluyo una edición paleográfica de la citada fábula a partir de la edición princeps de Baltasar Vivien que puede localizarse en la Biblioteca-Fundación «Manuel Ruiz Luque» con la signatura 15240. He modernizado la ortografía, acentuación y puntuación según la normativa vigente de la Real Academia Española. Por lo que se refiere al uso de mayúsculas, sólo he mantenido aquellas que poseen una relevancia semántica y que, en la mayoría de los casos, pertenecen al acervo mitológico. Agradezco a D. Manuel Ruiz Luque, alma de la citada Fundación, así como a su director, D. José Antonio Cerezo, la inmensa ayuda prestada en la labor de documentación que ha precedido este trabajo, así como el interés y la confianza mostrados en mis investigaciones sobre el montillano. 


\section{Miguel de Barrios y la diégesis mítica}

En el feraz proceso de asimilación de la herencia hispánica, Miguel de Barrios no quiso renunciar al inagotable caudal compositivo que el mito clásico le ofrecía, pese a que el ambiente de la comunidad judía de Ámsterdam no fuera especialmente proclive -como cabía esperar- a la tradición mitológica ${ }^{9}$. La escuela culta, siguiendo la fértil estela de las fabulación gongorina tanto grave -el Polifemo- como jocosa -la Tisbe-, había transitado ese doble camino con maestría y deparado muestras excelentes, serias -Villamediana, Jáuregui, Bocángel o Lope de Vega- y burlescas -Pantaleón de Ribera, Colodrero de Villalobos, Jacinto Alonso Maluenda o Polo de Medina, entre otros muchos-. El poeta exiliado debía acometer, bien avanzada la centuria secentista, la ardua tarea de rescribir el mito con su personal caligrafía y pergeñar sus obras procurando esquivar los senderos ya ajados de sus predecesores peninsulares.

A propósito de la concreción de esta materia mitológica, puede afirmarse que Miguel de Barrios aprehendió con apasionamiento los distintos modos de enunciación experimentados por el mito en la lírica áurea, cuya formulación englobaba, al menos, las tres funciones básicas pergeñadas por el montillano ${ }^{10}$. Así, en sus dos libros más representativos -Flor de Apolo ${ }^{11}$ y Coro de las Musas-, las leyendas mitológicas se convierten en oportunos exempla de la peripecia vital de unos personajes -o de sí mismo-, amparados casi siempre en el contexto de una historia amorosa. Los Triunfos de Amor de Miguel de Barrios -incluidos en la musa Érato de Coro de las Musasconstituyen un paradigma excelente de este primer caso $^{12}$, ya que muchas de las

9 De hecho, tanto Flor de Apolo como Coro de las Musas fueron duramente censuradas en Ámsterdam por su contenido mitológico. Sobre esta polémica, véase H. den Boer, op. cit., págs. 85-87. Para la oposición de los judíos a la tradición clásica y en especial a la mitología- puede consultarse el estudio de M. Carmilly-Weinberger, Censorship and Freedom of Expression in Jewish History, Nueva York, Sepher Hermon, 1977.

10 Juan Matas Caballero argumenta, con la brillantez acostumbrada, que «en el uso generalizado de la mitología los poetas áureos pretenden expresar y formular poéticamente todos los registros que contienen las historias de los héroes y dioses paganos, a través de los más variados y diversos procedimientos y desarrollos literarios, desde la simple alusión mítica a la más complicada perífrasis mitológica y, de manera especial, recrearán el genuino género del Barroco: la fábula mitológica», «La mitología, campo de tiro, en la batalla de los estilos poéticos: Jáuregui y Pérez de Montalbán», en G. Cabello Porras y J. Campos Daroca (coords.), Poéticas de la Metamorfosis. Tradición clásica, Siglo de Oro y Modernidad, Universidad de Málaga / Universidad de Almería, Málaga, 2002, págs. 283-320. Recientemente, este espléndido trabajo ha sido recogido por su autor en Espada del olvido. Poesía del Siglo de Oro a la sombra del canon, Universidad de León, Secretariado de Publicaciones, 2005, págs. 199-238.

11 F. J. Sedeño Rodríguez esgrime una primera clasificación de las fábulas mitológicas de Flor de Apolo, «según aparezca el tema mítico en composiciones de carácter lírico, como tema exento o en meras alusiones mitológicas», «Introducción» a Miguel de Barrios, Fábulas mitológicas, op. cit., pág. 28. Esta estructura puede aplicarse grosso modo a la conformación de la materia mitológica en Coro de las Musas, aunque con sutiles modificaciones.

12 He estudiado con pormenor dicho poemario en La poesía amorosa, y «Los Triunfos de Amor de Miguel de Barrios, ¿un cancionero postpetrarquista?», en C. Mata y M. Zugasti (eds.), Actas del Congreso «El Siglo de Oro en el nuevo milenio. I.», Eunsa, Pamplona, 2005, 765-776. 
composiciones que integran dicho corpus acusan esta función ejemplarizante del mito. Tampoco va a desdeñar nuestro poeta el tratamiento del mito -ya sea en su vertiente en seso, burlesca o jocoseria- como un elemento desgajado de la fusión mítica, con una intención claramente estética que concede a la descriptio y a la narratio una especial relevancia en la arquitectura de la fábula mitológica. Será esta particular reescritura, la que permita a Barrios incorporar a la narración mitológica una enriquecedora mixtura de tradiciones diversas a partir de los postulados fundamentales del judaísmo. Por otro lado, en este somero bosquejo de la diégesis mítica en la obra poética de Barrios deben mencionarse otros procedimientos como la alusión, la perífrasis, la actualización mitológica o la metáfora, que Barrios usó con profusión y que evidencian, una vez más, la dilatación -hasta finales del siglo XVII- de una práctica muy difundida entre los autores de nuestros Siglos de Oro ${ }^{13}$.

Si bien es cierto que Daniel Leví explotó con soltura las tres enunciaciones del mito clásico propuestas con anterioridad, una lectura atenta de sus dos libros más ambiciosos, Flor de Apolo y Coro de las Musas, nos permite apreciar la especial propensión del autor sefardí hacia la segunda de ellas, que abordaba el mito de manera independiente y que hallaría en el género de la fábula mitológica un eficaz acomodo. Bajo la estela de Góngora, Colodrero de Villalobos, Pantaleón de Ribera o Polo de Medina, Barrios compuso un total de nueve ${ }^{14}$ fábulas mitológicas en metros diversos, cinco de las cuales son claramente burlescas (Alfeo y Aretusa, Júpiter y Calisto, Vulcano y Venus, Adonis y Venus y Pan y Siringa), una grave (Eco y Narciso), otra (Polifemo y Galatea) que podría considerarse también burlesca -aunque está más cerca de la composición paródica-, un divertimento agudo muy breve (Peleo y Tetis) -con abundantes rasgos festivos-, y una fábula compuesta en spoudaiogéloion o estilo jocoserio (Prometeo y Pandora), que analizaremos a continuación. Muchas de ellas fueron incluidas en Flor y luego reeditadas -con modificaciones de gradación desigual- en Coro; así sucede con las fábulas de Alfeo y Aretusa, Júpiter y Calisto, Vulcano y Venus, Adonis y Venus y Eco y Narciso. Otras, en cambio, sólo aparecen en Flor -Polifemo y Galatea- o en el Coro -Prometeo y Pandora, Pan y Siringa y Peleo y Tetis-. Con este inventario mítico, Barrios

13 Dicha práctica no sólo se circunscribe a la lírica, sino que también puede hacerse extensible a otros géneros literarios como la novela pastoril, como ha señalado con acierto V. Cristóbal López, quien establece una brillante casuística mítica a tenor de cinco funciones: alternancia, proyección, ampliación, ejemplificación y denominación, «Mitología clásica y novela pastoril», en I. Colón Calderón y J. Ponce Cárdenas (eds.), Estudios sobre Tradición Clásica y Mitología en el Siglo de Oro, Ediciones Clásicas, Madrid, 2002, págs. 109-122.

14 Serían diez si consideramos que la Fábula de Cristo y la Magdalena fue compuesta por Miguel de Barrios. Esta hipótesis ha sido defendida por A. Alatore, «La fábula burlesca de Cristo y la Magdalena, de Miguel de Barrios», Nueva Revista de Filología Hispánica, XLI, 1993, núm. 2, 401-458. Se trata de una cuestión muy controvertida y, hasta la fecha, no han aparecido argumentos ni en contra ni a favor de dicha autoría. 
se convertía, sin lugar a dudas, en uno de los más fecundos cultivadores del género fabulístico de su tiempo ${ }^{15}$.

La prolijidad de su pluma sería, en efecto, una de los pocos «atributos» que redimen a Daniel Leví en el escrutinio realizado por José María de Cossío. En un apresurado acercamiento al montillano, sus Fábulas mitológicas recogen seis de sus nueve fábulas, que cataloga de forma fragmentaria estableciendo la filiación entre el exiliado sefardí y Góngora, Quevedo, Calderón o Polo de Medina ${ }^{16}$. Pese a la vaguedad de su análisis, se puede espigar, no obstante, un trazo preciso que nos interesa traer a colación. Dice Cossío: «No aportó al tratamiento del género novedad alguna estimable, pero subrayó matices que nos ayudan a comprender mejor el carácter de estos poemas» ${ }^{17}$. A mi juicio, son precisamente estos matices los que se han convertido, en los últimos años, en argumentos irrefutables para recuperar a estos autores que, como Barrios, desarrollaron su obra en las últimas décadas del siglo XVII, siempre a la sombra de las grandes individualidades de nuestro Siglo de Oro, pero incardinados de lleno en su magisterio, según estamos comprobando.

Sin embargo, Cossío pasó por alto algún que otro matiz y, como hemos señalado, omitió tres de los epilios compuestos por Miguel de Barrios, entre ellos esta Fábula de Prometeo y Pandora que aquí nos ocupa, uno de los más raros y originales de su inventario fabulístico por el sugestivo proceso de reescritura a que el autor somete las fuentes clásicas ${ }^{18}$. Este olvido resulta más llamativo aún si tenemos en cuenta que sí da, en cambio, noticia de un manuscrito anónimo que contiene una curiosa fábula alegórica titulada Ecos de la Musa Trasmontana o Prometeo ${ }^{19}$. Partiendo de las notas que sobre dicho texto proporciona Gaspar Garrote Bernal -en su modélico análisis sobre la pervivencia del mito de Prometeo en la lírica áurea-, intuimos que un minucioso cotejo entre ambas fábulas arrojaría sutiles concomitancias como el carácter alegórico -que las dos comparten-, la creación de Pandora -a semejanza de los dioses- a manos de

15 A. Alatorre comentaba a este respecto que «hacia 1675 era Barrios el campeón de los poetas españoles en cuanto a número de fábulas burlescas, el que más afición había mostrado a esa especie de juego de ingenio. Y como después de 1675 las fábulas burlescas entraron en decadencia, puede decirse que las suyas son el remate del género», loc. cit., pág. 402.

16 J. M. de Cossío, Fábulas mitológicas en España, Espasa-Calpe, Madrid, 1952, págs. 203-206. Aparte de estas notas que el compilador recoge en el cap. XXIII -dedicado a la "Corriente calderoniana"-, dedica algunas impresiones más en el XXVI, donde se refiere a los "Romances mitológicos burlescos" (pp. 312317).

17 J. M. de Cossío, loc. cit., pág. 316.

18 Esta omisión de J. M. de Cossío fue señalada por A. Alatorre, op. cit., pág. 420, nota 35.

19 J. M. de Cossío, op. cit., págs. 59-64. J. Lara Garrido se ha referido a dicho texto como el «único tratamiento exento» del mito prometeico en la poesía española del siglo XVII, «Los retratos de Prometeo (Crisis de la demiurgia pictórica en Paravicino y Góngora)», Edad de Oro, VI, 1987, pág. 138, n. 27. 
Prometeo, la intervención de la diosa Atenea o la sugerente fusión del mito prometeico con el semítico de Pigmalión ${ }^{20}$.

\section{La Fábula de Prometeo y Pandora. Disposición y sentido}

La Fábula de Prometeo y Pandora se inserta en Urania, la musa celeste que abre el Coro de las Musas. Va precedida de dos sonetos-prólogo: el primero de ellos -como sucede en las restantes secciones del poemario- elogia al patrocinador de la obra, Francisco de Melo; el segundo, en cambio, presenta el contenido de la fábula y expone algunas de las claves interpretativas necesarias para descifrarla ${ }^{21}$. Con respecto a la paginación, Daniel Leví -o su impresor- incurre en varios errores. Así, aunque el epilio debería ocupar las páginas 45-70 de Coro, comienza en efecto en la página 45, pero de la 48 salta a la 25 , continuando después la secuencia numérica lógica hasta la página $48^{22}$.

La composición se dispone en 223 cuartetas de romance, un cauce métrico en el que Barrios ya había vertido varios epilios burlescos por haber mostrado -desde la Tisbe gongorina- una especial ductilidad para el estilo jocoso y que ahora parecía acomodarse con idéntica facilidad a la dicción jocoseria ${ }^{23}$. La estructura de la diégesis mítica podría obedecer al siguiente esquema:

20 G. Garrote Bernal, «Tradición mitológica y contextualización literaria: Prometeo en la lírica española del Siglo de Oro», Cuadernos de Filología Clásica. Estudios latinos, 4, 1993, 233-255. Este espléndido trabajo me hizo reflexionar por primera vez sobre este raro epilio de Barrios que hoy doy a conocer al final de estas páginas. Lamentablemente, al cierre de estas páginas, mis gestiones para consultar dicho texto todavía no han dado fruto, aunque esperamos poder cotejarlo en breve y precisar en un próximo trabajo alguna conclusión a este respecto.

21 Coro de las Musas se halla escindida en nueve partes, siguiendo la misma disposición que el Parnaso Español de Francisco de Quevedo. Urania, musa de la Astronomía, canta el «Mundo Elemental»; Terpsícore, musa de la Geografía, describe las distintas provincias hispanas, la genealogía austriaca y el Reino de Portugal; Clío, musa panegírica, elogia varias ciudades, excelsos poetas y personajes ilustres; Érato, musa amorosa, canta sus «Triunfos de Amor»; Euterpe, musa pastoril, entona sus «Zampoñas Pánicas»; Polimnia, musa lírica, expone sus «Donaires mélicos, satíricos y jocosos»; Talía, musa Cómica celebra los «Epitalamios de Himeneo»; Melpomene, musa de la poesía fúnebre, lamenta la muerte de personajes ilustres y revela algunos «desengaños» y, por último, Calíope, musa moral, expone sus «poesías ejemplares». El corpus se cierra con la «Música de Apolo», que ya se había recogido en Flor de Apolo y que aquí se mantiene con algunas modificaciones, «Las Gracias del Parnaso» y finalmente «Naturaleza y Arte de las Musas». Como era habitual en este tipo de poemarios, las páginas preliminares incluyen varios elogios a su patrocinador, Francisco de Melo, otros tantos a Miguel de Barrios, un índice general, un singular prólogo y un jocoso romance que el autor dedica a su libro.

22 He podido apreciar estas deficiencias en las ediciones del Coro disponibles en la Biblioteca Nacional de Madrid (R 5990, R 7072, R 7575, R 7634, R 13036 y U 1789) y en la Biblioteca Fundación «Manuel Ruiz Luque», (15140, 15141 y 15240).

23 Si bien es cierto que el romance -culto y popular- fue una de las estrofas más ejercitadas del período áureo, según puede apreciarse en la obra de Góngora, Lope de Vega, Quevedo, etc., la octava real, la silva clásica o la silva pareada u ovillejo -ésta última siempre en combinación con otros esquemas métricos como el propio romance- también se acomodaron con notable éxito a la fabulación mitológica. El Polifemo de Góngora, La Filomena de Lope de Vega, la Europa de Villamediana o el Alfeo de Colodrero 
I. Introducción (vv. 1-72).

II. Presentación de Prometeo (vv. 73-96).

III. Prometeo figulus: la creación de la efigie (vv. 97-120).

IV. Descriptio puellae (vv. 121-184).

V. Efectos de amante y presentación de Minerva (vv.185-192).

VI. Primera sermocinatio de la diosa, donde aconseja el robo del fuego divino (vv. 193-232).

VII. Aprobación de Prometeo y ascenso del joven al Olimpo (vv.233-256).

VIII. Asalto a la morada de los dioses y reacción de sus habitantes (vv. 257-280).

IX. Cosmografía celeste: constelaciones del hemisferio boreal (vv. 281-360).

X. Descripción de los signos del Zodíaco y sus correspondientes cronografías primaveral, estival, otoñal e invernal (vv. 361-476).

XI. Segunda cosmografía celeste: constelaciones del hemisferio austral (vv. 477-577).

XII. Llegada de Prometeo a la esfera solar y robo del fuego divino (vv. 578-597).

XIII. Consecuencias del hurto y huida de Prometeo (vv. 598-645).

XIV. Restitución del fuego a los hombres, animación de la estatua y rendición de Prometeo ante su belleza (vv. 646-661).

XV. Segundo parlamento de Minerva: exposición de motivos, nominación de Pandora, catálogo de gracias y furia de Júpiter (vv. 662-749).

XVI. Unión de Prometeo y Pandora. Celebración del himeneo (vv. 750-845).

XVII. Irrupción de Júpiter y rapto de Prometeo (vv. 846-861).

XVIII. Asedios del celoso tonante y firmeza de Pandora (vv.862-873).

XIX. Auxilio de Hércules y liberación de Prometeo, a quien toma por maestro (vv. 874-885).

XX. Iniciación del héroe en la ciencia astrológica y unión de los amantes (vv. 886-897).

La rara filigrana mitológica que concibe Miguel de Barrios no mantiene una relación directa con los hipotextos clásicos que habían abordado la historia prometeica ${ }^{24}$, Hesíodo -Teogonía, 507-616, Los Trabajos y los Días, 43-105-, Esquilo, Prometeo encadenado, Platón, Protágoras ${ }^{25}$, u Ovidio, Metamorfosis, I 80-3. Pese a esta filiación indirecta pueden testimoniarse en el poema algunos motivos vinculados a alguno de estos relatos. Baste citar, a modo de botón de muestra, la alusión de Minerva al engaño que el hijo de Jápeto profiere a Zeus, inserto en la fuente hesiódica: «Desde que a Jove engañaste, / está el mundo como ciego, / porque el viento que le diste / apagó la luz del suelo» (vv. 201-204).

son paradigmas excelentes de esta tendencia. Sobre la renovación crítica en torno al epilio barroco más conocido, puede verse la reciente edición de Jesús Ponce Cárdenas: Luis de Góngora, Fábula de Polifemo y Galatea, Madrid, Cátedra, 2010. Del mismo estudioso pueden consultarse asimismo dos monografías: Cinco ensayos polifémicos, Málaga, Universidad de Málaga, 2009; El tapiz narrativo del Polifemo: eros y elipsis, Barcelona, Universitat Pompeu Fabra, 2010.

24 El mito de Prometeo ha sido objeto de numerosos trabajos de diversa índole, entre los que pueden reseñarse los siguientes: J. Duchemin, Prométhée. Le mythe et ses origines, Les Belles Lettres, París, 1974 ; P. Lévêque y L. Séchan, Les grandes divinités de la Grèce, Armand Colin, París, 1990, págs. 51-61; L. Séchan, El mito de Prometeo, Editorial Universitaria de Buenos Aires, Argentina, 1960; A. Ruiz de Elvira, «Prometeo, Pandora y los orígenes del hombre», Cuadernos de Filología Clásica. Estudios latinos, 1, 1971, 79-108 y «Nuevas puntualizaciones sobre Prometeo», en Homenaje a Antonio Tovar, Gredos, Madrid, 1972, 437-447; J. P. Vernant, «El mito prometeico en Hesíodo», Mito y sociedad en la Grecia antigua, Siglo XXI, Madrid, 1982, 154-169 y «Prometeo y la función técnica», Mito y pensamiento en la Grecia antigua, Ariel, Barcelona, ${ }^{2} 1985$, 242-252 y C. García Gual, Prometeo: mito y tragedia, Hiperión, Madrid, 1995.

25 Para un análisis riguroso de las tres primeras fuentes, véase C. García Gual, loc. cit., págs. 23-157. 
Su original lectura del mito de Prometeo parece haberse inspirado en la fértil conjunción de dos tradiciones distintas: la mitográfica y la calderoniana. La primera de ellas remite, con algunas variantes, a los relatos sobre el Titán recogidos en la Philosophia secreta de Juan Pérez de Moya -capítulo XL De Prometheo ${ }^{26}$ - y la primera parte del Teatro de los Dioses de la Gentilidad, de Fray Baltasar de Vitoria -Libro IV, cap. XXII, De Prometeo ${ }^{27}$-, dos manuales que, por otra parte, eran bien conocidos por nuestro autor. Muy influenciadas por toda la tradición mitológica precedente -G. Boccaccio y su Genealogia deorum así como sus continuadores, Lilio Gregorio Giraldi, Vincenzo Cartari y Natale Conti-, ambas recopilaciones habían tenido gran difusión durante los siglos XVI y XVII ${ }^{28}$. Por otro lado, y como ha señalado con acierto el profesor Garrote Bernal, muchas de las reinterpretaciones que el mito prometeico experimenta en la poesía española del Siglo de Oro no aluden a fuentes antiguas sino que expolian con frecuencia estas fuentes secundarias más o menos contemporáneas (Alciato, Cartari o Pérez de Moya) que funcionan como eslabones entre la Antigüedad clásica y la lírica áurea $^{29}$. La segunda, en cambio, imbrica al capitán criptojudío -dramaturgo, además de poeta- con Calderón de la Barca, al que siempre profesó una admiración profunda, y a su epilio jocoserio con la comedia o intermezzo de asunto mitológico que el genial autor concibiera en torno a 1670, La estatua de Prometeo ${ }^{30}$. Aunque hay diferencias sustanciales entre la pieza calderoniana y la fábula del montillano, creemos que los dos autores llevan a cabo -en lo que respecta a su arquitectura básica- una reformulación del mito muy similar, coincidente incluso en los modelos seleccionados ${ }^{31}$. Por lo que se refiere a Calderón, nos presenta éste a un Prometeo rendido ante una copia de Minerva (luego Pandora) que él mismo ha modelado con barro, la que cobrará vida con un rayo hurtado a Apolo. Tras una sarta de equívocos, la comedia concluye con el matrimonio entre la diosa y el titán. Así mismo, la fábula de Barrios relata la historia de amor de

26 J. Pérez de Moya, Philosophia secreta, Biblioteca Castro, Madrid, 1996, págs. 811-817.

27 Fray Baltasar de Vitoria, Teatro de los Dioses de la Gentilidad, Antonia Ramírez, Salamanca, 1620.

28 J. Seznec, Los Dioses de la Antigüedad en la Edad Media y el Renacimiento, Taurus, Madrid, 1985, pág. 260. Actualmente estos textos son de muy fácil acceso en las modernas ediciones siguientes: Le immagini degli Dei di Vicenzo Cartari, Caterina Volpi (ed.), Ediciones de Luca, Roma, 1996 y Natale Conti, Mitología, R. M. Iglesias Montiel y M. C. Álvarez Morán (eds. y trads.), Universidad de Murcia, Servicio de Publicaciones, 1988.

29 G. Garrote Bernal, op. cit., pág. 255.

30 La datación de esta obra ha estado rodeada de una gran controversia, aunque las evidencias aportadas por su editora más reciente demuestran con bastante solidez que la pieza debió representarse, por primera vez, en diciembre de 1670 con motivo del cumpleaños de la reina madre, Mariana de Austria, "General Introduction. 3. Performances of La estatua de Prometeo» a P. Calderón de la Barca, La estatua de Prometeo, M. Rich Greer y L. K. Stein (eds.), Reichenberger, Kassel, 1986, págs. 93-96.

31 M. Rich Greer comenta: «Although Calderón could also have read the Prometheus story in translations of Hesiod, or in a variety of earlier mythographers, his most likely source for the details of the story would have been the mythological encyclopedias of Juan Pérez de Moya or Fray Baltasar de Vitoria», loc. cit., pág. 129. 
Prometeo y Pandora, formada también con barro por el astuto joven que, después de crear su obra, se siente arrebatado por una pasión irresistible. Al igual que Calderón, el poeta de Montilla acomete una fértil simbiosis entre el mito clásico de Prometeo y el semítico de Pigmalión ${ }^{32}$ : «Tan Pigmalión se rinde / a lo que compone él mismo; / que si su beldad le incita, le suspende su respeto» (vv. 105-108). De esta forma, el vínculo sentimental que une a los dos protagonistas -apenas referido en la tradición antigua ${ }^{33}$ se convierte en el auténtico leitmotiv que da sentido a la diégesis mítica, sellado con el ansiado himeneo cuando Prometeo, con el fuego robado a los dioses, insufla vida a su bella efigie.

En este sentido, puede afirmarse que Daniel Leví de Barrios pergeña un original epilio jocoserio, seleccionando con esmero, a partir de los cinco componentes básicos -o mitemas- asociados con el relato prometeico, la materia mitológica que mejor se aviene a sus intereses particulares. Estos mitemas definían a Prometeo según los conceptos siguientes: «Bienhechor y civilizador de la humanidad», «Creador-alfarero de la humanidad», «Ladrón del fuego divino», «El castigo eterno» y «Liberación final y relación con la diosa Tetis» ${ }^{34}$. Para bosquejar el lienzo de los amores entre Prometeo y Pandora, el autor otorga mayor relevancia a los mitemas 2 y 3 -modelación de la imagen con barro y hurto del fuego divino- y reduce, en cambio los mitemas 1, 4 y 5 a muy pocos versos.

A través de la relectura del mitema 2, Barrios concibe a Pandora como obra de ese Prometeo figulus ${ }^{35}$-tan cercano al Deus artifex del Génesis- mencionado como el creador de la especie humana ${ }^{36}$ por Ovidio en sus Metamorfosis (I, 82), entre otros autores, y asimilado después por la tradición mitográfica renacentista y barroca -Pérez

32 P. Grimal relata la leyenda semítica de Pigmalión: «un rey de Chipre que se enamoró de una estatua de marfil que representaba a una mujer. A veces se decía que la había esculpido él mismo. A impulsos de su pasión, pidió a Afrodita, en ocasión de una fiesta de la diosa, que le concediese una esposa que se pareciera a la estatua. Cuando volvió a su hogar, vio que ésta estaba viva. Casó con ella, y tuvo una hija, llamada Pafo, que, a su vez, fue madre de Cíniras», loc. cit., págs. 428-429. Ovidio (Metamorfosis, X, 243 y sigs.) o Virgilio (Eneida, I, 343 y sigs.) son algunos de los autores clásicos que recogen este relato.

33 Parece que Hesíodo habría mencionado esta unión de Prometeo y Pandora a través de la alusión a su hijo Deucalión, el fundador de la estirpe helénica, A. Ruiz de Elvira, «Prometeo, Pandora», págs. 82, Mitología clásica, Gredos, Madrid, ${ }^{21984, ~ p a ́ g . ~} 261$ y C. García Gual, op. cit., pág. 42. P. Grimal, en cambio, no recoge este dato y sostiene que Prometeo es esposo de Clímene o de Celeno, Diccionario de mitología griega y romana, Paidós, Barcelona, ${ }^{4} 1989$, pág. 135.

34 Seguimos la atinada metodología expuesta por G. Garrote Bernal, op. cit.

35 Esta asociación de Prometeo como artifex está ausente en Hesíodo, Esquilo y Platón y aparece por primera vez en un autor cómico del siglo IV Filemón. Más tarde, además de Ovidio, la mencionan Pausanias, Apolodoro o Juvenal, C. García Gual, op. cit., págs. 61-62. Sin embargo, como recuerda E. R. Curtius, la simbiosis entre Prometeo y el Creador se produjo con posterioridad, Literatura europea y Edad Media latina. II, Fondo de Cultura Económica, México, 1984, pág. 757.

36 Una exposición modélica sobre las controversias que suscita este Prometeo-demiurgo pueden consultarse en A. Ruiz de Elvira, «Prometeo, Pandora», págs. 154-156. 
de Moya y Fray Baltasar de Vitoria ${ }^{37}$-. Frente a la ausencia de fisuras del relato genésico, estas fuentes hacen referencia a la creación de «figuras» de barro sin distinción de sexo (Ovidio), a un «hombre» al que llaman Pandora (Pérez de Moya) o bien a una «estatua de barro» o «figura» «retrato al natural de un hombre» (Fray Baltasar de Vitoria). El autor sefardí, por su parte, elude desde el principio estas vacilaciones e identifica su efigie -que será más adelante nominada como Pandora por Minerva- con una bella mujer, en cuyo retrato se detiene ampliamente (vv. 121-184) siguiendo un orden ascendente (de los pies a la cabeza) que invierte los cánones ecfrácticos habituales impuestos por el Petrarquismo ${ }^{38}$.

Resulta curioso, sin embargo, que Barrios no aglutine en su epilio los mitemas 2 y 3, lo que le hubiera permitido incorporar, como a muchos poetas áureos -Góngora, Paravicino o Quevedo-, una fecunda reflexión sobre la demiurgia artística ${ }^{39}$. Prefiere, en cambio, el poeta judío modular este mitema 3 -ladrón del fuego divino- mediante una orquestación más original en la que hace confluir en el primer parlamento de Minerva al Prometeo-benefactor (de la estirpe humana) con el Prometeo-usurpador (del fuego divino), lo que le permite consolidar el hilo conductor del relato: «Si lo intentas animar, / procura la luz de Febo, / restitúyesela al mundo, / le darás alma de fuego» (vv. 209212). En este sentido, recordemos que algunos hipotextos clásicos (Lactancio, Higinio o Luciano) conferían en efecto a Prometeo la tarea de haber conformado el primer cuerpo humano, pero no así su alma, la que sólo podía ser insuflada por una divinidad, Atenea en este caso. Sin embargo, otras fuentes antiguas (Servio o Fulgencio) afirman que es el mismo Prometeo quien, tras la creación de su efigie, roba el fuego divino ayudado por Minerva para poder animarla ${ }^{40}$. Esta última tradición es la que recogen más tarde Boccaccio, Pérez de Moya o Baltasar de Vitoria y se dilatará, como vemos, hasta Miguel de Barrios, donde será también el joven providente quien, después de hurtar la luz febea, la devuelva a los hombres y anime la bella imagen (vv. 646-653): _

\footnotetext{
Vuelve la luz a los campos que publican floreciendo a Minerva por su aurora,
}

37 Juan Pérez de Moya, op. cit., pág. 811 y Fray Baltasar de Vitoria, p. 489.

38 Este retrato de Pandora no difiere en exceso de las restantes composiciones ecfrásticas de Barrios a las que he dedicado algunas notas en «Una aproximación al retrato poético femenino». A propósito de este sugerente microgénero, pueden consultarse los trabajos de J. Ponce Cárdenas, «La descriptio puellae en las fábulas mitológicas de Miguel Colodrero de Villalobos», Angelica, 9, 1999, pp. 77-88 o J. I. Díez Fernández, «Pequeña puerta de coral preciado ¿con lengua?», Calíope, 12, 2, 2006, pp. 33-56.

39 Sobre esta fructífera mixtura y su asimilación con la creación pictórica y poética en la lírica áurea, véase E.L. Bergmann, Art Inscribed: Essays on Ekphrasis in Spanish Golden Age Poetry, Harvard, Cambridge (Mass.), 1979, especialmente el capítulo «The Expression of an Artistic Dilemma in the Allegorization of the Myth of Prometheus», págs. 71-120; J. Lara Garrido, op. cit., y G. Garrote Bernal, op. cit., págs. $240-245$

40 A. Ruiz de Elvira, «Prometeo, Pandora», pág. 156 y C. García Gual, op. cit., pág. 62, n. 8. 


$$
\begin{aligned}
& \text { por su sol a Prometeo. } \\
& \text { Baja al Cáucaso en que anima } \\
& \text { la hermosa estatua, que luego } \\
& \text { toma en el alma la voz, } \\
& \text { y en su impulso el movimiento. }
\end{aligned}
$$

Esta particular reescritura mítica contempla además una serie de innovaciones dispositivas muy sugerentes, integradas por Miguel de Barrios en la articulación de su epilio mediante las técnicas siguientes: la reducción de algunos pasajes de la historia prometeica -el castigo eterno (vv. 878-881) ${ }^{41}$ o la liberación final (vv. 882-885)-, a cada uno de los cuales dedica una sola cuarteta y la supresión de la relación del titán con la diosa Tetis ${ }^{42}$, sustituida por la unión de los amantes; amplificaciones de carácter descriptivo moteadas de sutiles juegos jocosos que vulneran el estilo grave o la inclusión de sermocinationes que constituyen un eficaz contrapunto a los dilatados segmentos narrativos y acentúan la quiebra con los modos enunciativos de los hipotextos precedentes.

Aunque en los límites de este trabajo resultaría muy difícil realizar un comento exhaustivo de todas estas novedades, sí quisiéramos, al menos, hacer una breve cala en las más significativas. Así, entre las finezas que el poeta criptojudío concede al terreno de la amplificatio cabe destacar, al inicio de la fábula, una sugestiva geographia mundi (vv. 1-40) que evidencia el conocimiento por parte de nuestro autor de las teorías cosmológicas de Copérnico -expuestas en su De revolutionibus orbium coelestium libri (1543)- que sustituyeron a las ya obsoletas de Ptolomeo e Hiparco, así como de los versos dedicados al origo mundi en las Metamorfosis ovidianas (I 5-88). Concluye esta cosmografía con un discurso ético -salpicado de motivos que recuerdan la tradición bíblica condenatoria del Cielo y el Infierno- donde el montillano expresa su pesimismo ante la degeneración espiritual que consume al ser humano en su tiempo (vv. 41-72). De modo muy similar se había expresado el mismo Hesíodo en Trabajos y Días -justo después del relato de Prometeo- al referirse a la degradación de la vida humana desde la primera Edad de Oro a través del «Mito de las Edades» ${ }^{43}$.

Mención especial merecen, las extensas amplificaciones que detallan las distintas constelaciones boreales -Osa Mayor, Dragón, Cefeo, Artofílace o el Boyero, Corona,

41 El castigo eterno experimenta en la fábula de Barrios una mutación más profunda, no sólo por su reducción sino, sobre todo, por la causa que lo motiva: El «galán de Europa»-como Barrios denomina al Tonante- lleva a Prometeo al Cáucaso, después de su himeneo con Pandora, por celos y no porque haya hurtado el fuego de los dioses, como queda de manifiesto en los versos siguientes: «Jove a lo lechuzo apaga / el candil de sus contentos, / por la que con el torcida / le da la luz de los celos» (vv. 846-849).

42 Curiosamente, no existen evidencias de este mitema en la lírica del Siglo de Oro, (G. Garrote Bernal, op. cit., 254).

43 C. García Gual, op. cit., pág. 38. También Ovidio menciona las cuatro edades del hombre en sus Metamorfosis (I 89-50). 
Hércules o el Arrodillado, Cisne, Casiopea, Perseo, Auriga, Serpentario, Saeta, Águila, Delfín, Pegaso, Andrómeda, Triángulo y Carnero (vv. 281-356)- y australes -Ballena, Orión, Erídano, Liebre, Can Mayor, Argo, Hidra, Cuervo, Centauro, Altar, Corona Austral, Peces (Dérceto), Fénix, Grulla, Hidro, Sagitario, Pavo Real, Ceneo, Ave del Paraíso, Mosca, Pez Grande, Dorado y Paloma (vv. 477-577) ${ }^{44}$. Ambas cosmografías celestes, concebidas por el poeta judío a partir de la Astronomica de Manilio ${ }^{45}$, de los Catasterismos de Erastótenes ${ }^{46}$ y del Atlas Coelestis seu Harmonia Macrocosmica de Andreas Cellarius (publicado en Ámsterdam en 1661), fundamentalmente, constituyen una muestra excelente del hábil manejo que poseía Barrios no sólo de la alusión mítica o de la mitología catasterística ${ }^{47}$, sino también de la cartografía astral coetánea ${ }^{48}$. Por otro lado, no podemos olvidar que la inclusión de todo este ingente material astrológico no era del todo casual, ya que también proporcionaba a Daniel Leví un medio muy adecuado para incluir en su fábula alguna reminiscencia del mitema 1 , que relacionaba a Prometeo con la invención de la Astrología y que había así había sido formulado, entre otros, por Juan de la Cueva en Los inventores de las cosas ${ }^{49}$ o Alciato en sus Emblemata, quien lo representa en la sección dedica a esta ciencia «oculta y misteriosa» ${ }^{50}$.

De espléndida factura es también la extensa descriptio puellae (vv.121-184), donde Barrios acomete, sin lugar a dudas, su retrato femenino más logrado sirviéndose de un tupido reticulado de ambivalencias metafóricas teñido de un sugerente erotismo ${ }^{51}$. Por último, baste señalar el gracejo de la miniatura epitalámica que relata el himeneo entre ambos protagonistas e incluye un divino cortejo nupcial cuajado de elementos festivos

44 Algunos de estos catasterismos son comentados por A. Ruiz de Elvira, Mitología clásica, págs. 470487.

45 M. Manilio, Astrología, F. Calero y M. J. Echarte (eds.), Gredos, Madrid, 1996. Miguel de Barrios cita expresamente al escritor itálico en el soneto-prólogo de la musa Urania.

46 Eratóstenes, Catasterismos, J. R. del Canto Nieto (ed.), Ediciones Clásicas, Madrid, 1992.

47 Para A. Ruiz de Elvira se llama catasterismo a «la conversión en constelación de un personaje o ser mitológico, y también a la constelación misma que así resulta, y que por su nombre, forma y cualidades se admitía que seguía siendo el mismo personaje o ser en cuestión, transformado en astro pero conservando en algún modo, más aún que en las metamorfosis ordinarias, su antigua personalidad o individualidad peculiar», Mitología clásica, pág. 470.

48 Hemos cotejado las representaciones catasterísticas de la Harmonia Macrocosmica y, en efecto, guardan una relación muy estrecha con las descripciones astrales trazadas por Barrios en su epilio.

49 G. Garrote Bernal, op. cit., pág. 235.

50 Se trata del emblema CII, Quae supra nos, nihil ad nos (Que con cuidado se alcanza la ciencia), A. Alciato, Emblemas, S. Sebastián (ed.), Akal, Madrid, 1985, págs. 136-137.

51 Por su calidad, el retrato de Pandora merece un estudio pormenorizado que sobrepasa las dimensiones de este trabajo. Como anticipo, sólo apuntaremos que esta composición ofrece una sutil aemulatio de la conocida alegoría de la dama como templo sostenido sobre «ebúrneas columnas». En este sentido, resulta imprescindible el modélico estudio de J. Lara Garrido, «Columnas de cristal: códigos y discursividades entre un soneto de Lope y un famoso romance anónimo», en A. Cruz Casado (ed.), El cortejo de Afrodita. Ensayos sobre literatura hispánica y erotismo, Anejos de Analecta Malacitana, 11, Málaga, 1997, págs. 23-68. 
-chistes, refranes, alusiones escatológicas, a veces muy chocarreras- que funcionan como desmitificadores de la materia mitológica y suponen un afortunado contrapunto a la consecución del relato mítico ${ }^{52}$.

Para concluir, las apresuradas notas de lectura en torno a la Fábula de Prometeo y Pandora de Miguel de Barrios que hemos ido espigando en las páginas precedentes revelan, en primer lugar, la existencia -junto a los Ecos de las Musa Trasmontana o Prometeo. Fábula alegórica- de otro tratamiento exento del mito de Prometeo en la poesía española del siglo XVII, desconocido hasta la fecha por haber salido de la pluma de una de esas gespleten zielen (almas en litigio) que se vieron obligadas a exiliarse a los Países Bajos, donde se gestaría y publicaría toda su producción literaria.

El montillano muestra en esta peculiar adaptación del mito una destreza compositiva que, en nuestra opinión, va mucho más allá de un ramillete de versos bien acabados. Se refleja ésta sobre todo en la espléndida armazón dispositiva imperante en toda la fábula, así como en el plano elocutivo que, aunque aparezca un tanto desvaído en algunos puntos, se incardina plenamente en la escuela culta. Los tintes jocosos que Miguel de Barrios da a su epilio, le permiten incorporar, por otro lado, sugerentes subversiones paródicas en los segmentos descriptivos, un hecho sin precedentes en la lírica de nuestros Siglos de Oro -con la única excepción del diálogo «Apolo» de Lope de Vega-, cuyos autores siempre habían acudido al relato del titán para asuntos graves (la experiencia amorosa, los avances tecnológicos o los encomios a la creación pictórica $)^{53}$. Del mismo modo, selecciona con esmero aquellos mitemas de la historia prometeica que mejor se avienen a su proyecto poético -manejando con habilidad hipotextos clásicos y contemporáneos- y los incorpora al decurso narrativo renovados mediante las consabidas técnicas amplificativas y reductivas o la recurrencia a la sermocinatio. Lejos de deshilvanar la diégesis mítica, estas extensas concesiones a la descriptio constituyen auténticos microtextos que exploran el discurso moral, el retrato poético, la cosmología celeste o el bosquejo epitalámico y evidencian la meditada arquitectura fabulística que nuestro autor lleva a cabo.

En definitiva, el epilio jocoserio incluido por Daniel Leví de Barrios en la musa Urania de Coro de las Musas viene a atestiguar que el mito de Prometeo, todavía a finales del siglo XVII, seguía inspirando algunas composiciones curiosas, como esta

52 J. Ponce Cárdenas ha dedicado páginas espléndidas a la configuración del género epitalámico en el Barroco, «El epitalamio barroco: algunas notas sobre la narratio mítica», Estudios sobre tradición clásica, págs. 83-94. Tales referencias pueden ahora ampliarse en la parte primera de la monografía, Evaporar contempla un fuego helado: género, enunciación lírica y erotismo en una canción gongorina, Anejos de Analecta Malacitana, 64, Málaga, Universidad de Málaga, 2006, pp. 27-116.

53 G. Garrote Bernal, op. cit., pág. 254. 
Fábula de Prometeo y Pandora, pervivencia que continuará en la centuria siguiente $\mathrm{e}^{54}$ y se dilatará hasta nuestros días.

\section{APÉNDICE TEXTUAL: FÁBULA DE PROMETEO Y PANDORA}

El mundo es una cebolla, que con telas de elementos y cielos, hace llorar al que le sirve de objeto. Consta de materias dos: una es el padre de Venus que no se pudre de nada, con ver las cosas del suelo. Otra, siempre está de humor, pero en tan mal pasatiempo, que de alterarse no escapa con poner tierra por medio. Vincula en sí cuatro simples, más con tan sabio concierto que concibe raras cosas, por ser la cópula de ellos Encendido por Egina tira saetas de incendios tonante el padre de Palas, con las pelotas de viento.

Encapótase la Ira, (que así llama a Juno el griego o al Aire) cuando la Tierra le da el vapor de los celos. Con una y otra ola el Mar la mariola está haciendo, y la alta, por la que mira sus vueltas con grave asiento. Suenan instrumentos varios, y a su son la opaca Tellus hace diversas mudanzas, aunque tiene los pies quedos. Parece diosa de partes, con las cuatro, que por medio del mar, hacen el cruzado dándose abrazos estrechos. Forman el salón del siglo, que con diáfano techo está colgado por sí, de varios países lleno.

Ríense unas gentes de otras, de los ojos tan espejos, que no mirándose a sí ven del prójimo el defecto. La hermosura de las flores,

54 Una reformulación diocechesca muy sugerente del mito prometeico es la de Giambattista Casti, A. Arce, «El mito de Prometeo y Pandora "metamorfoseado" por Casti en un cuento del settecento italiano», Epos, XIX, 2003, 259-276. 
salen en campos amenos. Todo en el mar de la vida nada, donde los soberbios

por ser los peces mayores, se tragan a los pequeños. Rápidas aves parecen los que remontan el vuelo con las garras al desgarro, y con el pico al sustento. El que vive como Bruto, acaba como Pompeyo, encontrando el precipicio donde busca el refrigerio. En la Menfis del engaño, es la culpa el Tolomeo que le ofrece los cariños para darle los venenos. Echa el altivo poder que se acatarra del viento roncas con ojos dormidos; en cuanto es cosa de sueño. El infierno de este mundo la gloria previene al recto, y de este mundo la gloria la infernal pena al perverso. Todo lo inculcó estudioso aquel hijo de Japeto que encontró a la Astrología en los caminos del Cielo. Tanto remontó el juïcio, que los celestes secretos alcanzó en el mayor monte; con más alto entendimiento. Intentó de las deidades hacer un raro modelo, que cifrase sus ideas, y dijese sus misterios. Para lograr su dictamen, con nombre de Prometeo que denota providente, le vino el serlo del cielo. Llamó la naturaleza y el hijo del movimiento, por salir con su mixtión a junta los elementos. De las cosas temporáneas, su saber magno arquitecto, en el sarao de los orbes sacó a danzar los efectos. Formó una imagen de barro, por tan superior concepto, que excediendo al artificio, admiró al entendimiento.

Tanto ocupó la atención en la forma de su cuerpo, que por hacerlo milagro no se valió del ejemplo. 
Tan Pigmalión se rinde

a lo que compone el mismo; que si su beldad le incita, le suspende su respeto.

Con ser tan grande su amor cree que no iguala al objeto, porque aun del lo imaginado no alcanza a lo verdadero. Lo propio que anhela ignora, en lo que no inculca viendo que es la mujer cielo grande, y el hombre mundo pequeño. Por pasar de lo admirado, la venera en lo suspenso, que a lo que juzga divino no llega ni el pensamiento. Demócrito hace al Amor, juzgando al ver sus pies ciego que sobre átomos de nieve fue este prodigio compuesto. Con ponerse en aguas forja sus amorosos incendios, de medio abajo de tierra, de medio arriba del cielo. Hermosura del non plus, pone en la modestia velo a las ebúrneas columnas donde está el hercúleo estrecho. Descubre otro en la cintura, y en el talle el aire bueno, con que le guía a sus brazos en figura de crucero.

Es un cabo cada mano que da tormentas de fuego, entrando en el mar de Amor, con cinco puntas de hielo. Medios globos son de jaspe los del mapa de su pecho, y sus pezones los polos de estos lácteos hemisferios. Dice Salomón que el mundo sobre un pilar está puesto: y este imita a su garganta, pues sustenta al mismo Cielo. Los siete órganos del rostro, de lo juicioso instrumentos, representan los planetas, con diferentes objetos.

Reverberados se encienden en las mejillas aquellos arreboles, procedidos de los solares reflejos. Puerta del cielo su boca ${ }^{55}$, se abre solo a lo perfecto, con las llaves de carmín

55 Para la operatividad de esta metáfora, véase el magnífico trabajo de J. I. Díez Fernández, "Pequeña puerta de coral preciado:¿con lengua?", Calíope, 12, 2 (2006), pp. 33-56. 
que traen sus blancos porteros.

Señal rojo indica guerras

de amor, en globo sereno,

donde las luces rasgadas,

publican sus rompimientos.

Arquímedes de alabastro

parte al sol el perfil bello,

que por abrasar las vidas

lo descubre en dos espejos.

Vías áureas son las cejas,

en el espacio de argento

que tiran ardientes flechas,

arcos de Amor pareciendo.

Globo de cristal la frente

queda sobre el firmamento

que con línea de marfil

se divide en dos luceros.

Cielo grande el de la idea, desatando el rubio pelo, parece que Etna de nieve por la cabeza echa fuego.

Arde en al aire de forma, que su primer movimiento para que al orbe no queme lo tiene por los cabellos.

Resulta la viva llama,

en el que de verla muerto,

por su insensible hermosura siente amorosos incendios.

Besa la estatua y la admira la Hija del intelecto,

que en Salomón tuvo trono,

y en los atenienses templo.

- «Oh, amante joven, (le dice)

cuantos hay entendimientos

son cuerpos, y la prudencia

el alma de todos ellos.

Si en este lance te falta, quedarás con estos cuerpos como el ciego sin bordón, como el niño sin maestro. Desde que a Jove engañaste, está el mundo como ciego, porque el viento que le diste apagó la luz del suelo.

Todo el saber ocupaste en formar ese portento que con carecer de vida, le da a tu amante deseo. Si lo intentas animar, procura la luz de Febo, restitúyesela al mundo, le darás alma de fuego. La diosa soy de las ciencias, que inmediatamente vengo, del que formó cuanto cifra

la rara imagen que has hecho.

$\mathrm{Al}$ dios vencí de las aguas, 
contra el anuncio guerrero que de la paz traje el ramo el arca del universo.

Por ti desharé sus sombras, si en el Olimpo barriendo las estrellas con mis alas, echas sus llamas al suelo. La Fortuna favorece al audaz, que con lo atento lleva delante el peligro, porque le guíe el trofeo. Sígueme: no te desmaye ser peligroso el empeño: que cuando importa al honor; cordura es buscar el riesgo». Dijo, y el mancebo sabio sigue su curso, y consejo sin que el volar por las nubes le impida el material peso. Tan blanco va con el susto, pasando el piélago aéreo, que salamandra de nieve parece dentro del fuego. Errante norte de pluma le guía al castillo excelso, que se guarnece de estrellas, por resistirse del tiempo. La fábrica admira el joven, andando con pies diversos, todo aprisa en sus espacios, todo juicioso en sus lejos. Nota como el gran palacio tiene superior gobierno, siendo los cielos sus altos, sus bajos los elementos. Atalaya de sus torres el rubio pastor de Admeto, enciende en ellas las lenguas que le sirven de correos. El soldado de Minerva lo asalta audaz, resolviendo robar los rayos que arroja por sus balcones Timbreo.

Toca a rebato el gran Móvil, tan velozmente violento, que perdiéndose de vista, lleva tras si los pequeños. A los ojos de Minerva dan voces, para que en ellos tenga Prometeo antojos, y los que pasan espejos. Sobre el combate discurre en diáfano colegio con dos cursos el globo aqueo, uno propio, y otro ajeno. El capitán de los astros al castillo del acceso, con estelíferas líneas 
pone luminosos cercos.

No hay cometa que no vuelva

la cola, en aquel encuentro,

que Juno y Cintia en sus nubes

huyen al polo del Euro.

Sesenta tropas de estrellas

ruedan en el campo etéreo,

con el lácteo arco, que pisan

los empirios corifeos.

Mil ciento setenta y cuatro

ígneas hachas, traen aquellos

que llama el griego asterismos,

y reinas el sabio regio.

Veinte y una al Bóreas corren,

doce escuadras de Timbreo

en el zodiaco, y guardas

veinte y una del crucero.

Marcha delante la Ursa

que del norte candelero,

guía a cuantos van en vela,

de luz el imán sirviendo.

Calisto de sed aúlla

las greñas encaneciendo

del que le niega sus aguas,

con calzones marineros.

Reconcentra el Dragón frío

del sol y la luna el fuego,

con las vueltas que a su eclipse

viene, de conchas cubierto.

En su reino experimenta

el etíope Cefeo

los enojos de la diosa

que lo trata como a un negro.

Guarda las osas Bootes,

en las espaldas teniendo

la Corona que dio Baco

a la que burló Teseo.

Da al Dragón como con porra

el que hasta en su nacimiento

supo más que las culebras,

torciéndoles los pescuezos.

Habla por boca de ganso

el de Leda amante ledo,

cantando al son de la lira

que de amor está muriendo.

La ambiciosa Casiopea,

no encuentra más que el despeño,

por tener la mala estrella

que destruye los imperios.

Armado de punta en blanco,

lleva el triunfante Perseo

la cabeza de Medusa,

por el serpentino pelo.

En sus terribles mudanzas

el celeste carretero,

con los hijos de Amaltea,

cabriolas está haciendo.

Echa mano a la Serpiente 
el dios de los que sin riesgo matan no tanto a las mulas, como a los tristes enfermos.

La Flecha hiere en un ala

al Águila que subiendo

con el idalio garzón,

sirve a Júpiter de asiento.

Vate escamoso el Delfín,

anuncia el naufragio adverso:

y la impiedad de Saturno

las señales de Equisectio.

Relincha al salir la Aurora

el caballo meduseo,

por las carreras rodado,

y por lo demás overo.

Atada Andrómeda grita,

aún más que al monstruo, temiendo

la envidia de las nereidas,

y el loco amor de Fineo.

Del reino de faraón

el Triángulo modelo;

su peste es la idolatría

que le avecina al Carnero.

Estos asterismos corren

desde el boreal extremo,

hasta donde hace el sol raya,

más que ninguno luciendo.

Quiere darle un sepan cuantos

con sus rasgos Prometeo,

por rubricarle en los signos

la cabeza de proceso.

Minerva le va a la mano,

con más vengativo intento,

metiéndole en el camino

que siempre el sol le hace tuerto.

Mira como echa en sus casas

todo doce, por los tercios

que en el juro de los meses,

le pagan los elementos.

Saca en su luciente coche

el dios de la rica Delfos

los cuatro tiempos del año,

con grande acompañamiento.

La gallarda primavera,

galas toda, y pasatiempos,

se descubre cuando el sol

en Aries pone los cuernos.

No sin templanza la goza

el natural movimiento,

para cuanto por su gusto

produce el dios de los huertos.

Suelta con flores abril,

al toro que en coso inquieto

brama, sintiendo el rejón

del planeta dominguero.

Abrázanse los mellizos,

dándose por sus efectos

un verde el mayo con Flora, 
y un rojo el Amor con Venus.

El seco, y ardiente estío

sale, cuando el rubio Delio

entra a poetizar con Cáncer

en la academia del cielo.

Amenazado de Alcides

ruge el animal nemeo,

contra las vidas y plantas

que destruye a sangre y fuego.

El sol, luciente Leandro

se arroja al granado estrecho

de la espigada doncella,

que tuvo por signo Sexto.

Galanes son de doña Alda

cuantos en la hermana de Ero

hace hormigas saqueadoras

Isis, con rostro trigueño.

Nace el otoño en las pajas

de Baco, y Pomona efecto,

por las vendimias muy sucio,

por las frutas muy enfermo.

Cuanto produce el estío gasta su húmedo heredero,

porque después de difunto

ve que no hay viña, ni huerto.

Ceres siembra sus semillas,

sacando la hija de Astreo

la balanza en que pesado

el sol se cree ligero.

Pasa por el Escorpión

con relámpagos y truenos:

y lloroso en Sagitario,

pone en los ojos sus velos.

Van las ramosas escuadras

sus verdes cabos perdiendo,

por caérsele las hojas

que juega el Carranza aéreo.

Los árboles son los grandes:

y el doliente Enrique el tiempo

que de fuerzas los desnuda,

dejándolos descubiertos.

Viejo, y temblando de frío,

nace el regañón Invierno,

con el fuego en las entrañas,

y la nieve en los cabellos.

Capricornio, Acuario, y Piscis, dan luz de como sintiendo

la terciana de sus meses,

está de ropas cubierto.

Gritan en la aérea cama

que pabellón tiene etéreo,

con mal de gota las nubes,

con fuentes frías el suelo.

Gatea aunque tiene canas

encapotándose enero,

en los gozos muy aguado,

y en las frialdades muy necio.

Arrebújanse en las puertas, 
y acuartélanse en los puestos, los rompidos por sus cuartos, los soldados por sus tercios. Sobre Eneas como Anquises muestran las palmas al fuego los que al Pan capro hacen migas, al cerdoso dios torreznos. Que mata Baco en las pipas y quema tabaco, es cierto, porque se vayan en humos cuantos se quedan en cueros.

Sobre los helados ríos de su país los flamencos, corren más que mala nueva, con ir calzados de hierro. No sin antojos sus casas, rizándose el blanco pelo, tienen al aire por peine, y delante los espejos. No se corren con los campos las aguas, porque trayendo varas con mocos las prenden, por el soplo que da el Cierzo. Todo esto trae por su línea el planeta que imprimiendo los accidentes del mundo, los saca a luz por rodeos. Junto a Piscis le hace salva aquel gran bajel de huesos que fue de Jonás sepulcro, y de Andrómeda recelo. Las nubes se orinan, cuando sale en el carro del Euro ventoseando Orión, por el ojo del invierno. Culebrea el estrellado río de Faetón, sirviendo al agua que bebe el Hidro el Canopo de terreno. Entre los pies del gigante salta la liebre: y ligero sobre ella pone el gran Can las columnas de su imperio. Late del sol salamandra el de Siria, que molesto al mundo por su calor, le da una vida de perro. Sin mástil la Nao, dispara sus cañones, balas siendo las piedras que cuaja el aire en la vejiga del fuego.

Guarda la Hidra a la Copa que su néctar niega al Cuervo porque dio una mala nueva al que lo cubrió de negro. Cosroes biforme el Centauro pone bajo de su reino la cruz que toman por guía 
los heraclios de Nereo.

Con boca de lobo, aúlla

el que vio como se hicieron

de los ripios que echó atrás

los hombres más duros que ellos.

Arde al Ara por el soplo

que lleva infortunios crespos

al que ara el cerúleo campo

con el cayado velero.

Brilla junto al Sagitario

la Corona que Baceo

dejó hablando por su madre

en la boca del infierno.

Dagón se envaina en escamas,

de Babilonia portento,

con el rostro de mujer

que engañó los filisteos.

Arde el Pájaro de Arabia

en los encendidos leños

que de si mismo renace

por tener humos de eterno.

Huye la estrellada Grulla,

el naufragio prediciendo

a las que junta en el aire, por ser ave de consejo.

La Abeja saca a volar

cuanta recogió Aristeo,

donde toman de sus luces

el saber guardar secreto

El pintado Hidro, parece

al mundo, en el Pó bebiendo, con lo hermoso por afuera

y lo insano por adentro.

Pisa el imperio del indio

Sagitario, que violento

figurando al español,

le tiene el pie en el pescuezo.

Es un Argos por la cola

la ave que ruedas haciendo

al carro las da de Juno,

en sus molinos de viento.

Armada contra el Centauro

la marimacha Ceneo,

en su opilación marcial

no le hace mal el acero.

El Ave del Paraíso

(que nunca sino es muriendo

baja a la Tierra) con raras

plumas, vuela por el cielo.

Trae en el rostro a la Mosca

la Sirena, y en el cuerpo

ocho astros camaleones,

beben por ella los vientos.

Estrellado en la celeste

sartén falta el Pez del vuelo,

diciendo: Allá lo veréis,

en el freír de los huevos.

Sobre la nube mayor 
el Dorado, va corriendo

Iris derecho en las lluvias,

y en las borrascas Santelmo.

La esposa de Nino alada

en el Babel del crucero,

murándolo con el giro,

lo exalta con el imperio.

Todo lo nota el hermano

del lascivo Epimeteo,

sobre la antártica rueda

que la fortuna le ha puesto.

Procura poner las manos

al sol, que de luces lleno

es en la etérea garganta

lamparón del universo.

Tan altamente veloz

descubre el fulgor febeo,

que con estar muy distante

lo coge en un pensamiento.

Guarda Minerva la luz,

en cuantas sombras de ceños

sirviéndole de linterna,

le da claro entendimiento.

Con la capa del juicio

la encubre, el rumor oyendo

que hacen a escuras los astros,

dándose palos de ciegos.

Corren por diversas partes,

y Júpiter al estruendo,

en laberinto de dudas,

no halla el hilo de lo cierto.

Cojea a sus alaridos

con cuatro caballos Delio,

dando a Leucotóe las gomas,

llamadas de Ovidio inciensos.

Súmeseles de la vista

como duende el que siguiendo

a Minerva, hace carbón

los que llegan a su fuego.

Da el arpista boquirrubio

sus uñas a los gatescos

ojos, que arañarle quieren

en lo oscuro reluciendo.

No hay esfera planetaria

que no abra el ojo a su incendio,

y encandilándose más,

más le ofrece el paso abierto.

El mozo escurre la bola

de cada esférico juego,

cogiéndola de fayanca

con la paleta de seso.

El cíclope de los rayos

grita de cólera ciego,

por el ojo que le lleva

el Ulises de los cielos.

Camina con tal temor

en la cueva del aprieto,

que si Palas le dice: anda, 
el garzón responde: quedo. A los peligros desuellan, y se entran en sus pellejos tanto, que de estos validos, parecen unos corderos.

Tímidos van a las manos del que con terribles dedos

en la boca de su cueva anda por los dos atiento. Minerva, no conocida, guía al astuto mancebo, que en el batel de la dicha sale del celeste puerto. Tira piedras como loco el divino Polifemo, al que los golfos del aire rompe con brillantes remos. Vuelve la luz a los campos que publican floreciendo a Minerva por su aurora, por su sol a Prometeo.

Baja al Cáucaso en que anima la hermosa estatua, que luego toma en el alma la voz, y en su impulso el movimiento. Admira lo que distingue, confusamente teniendo los ojos en el amante, y en la diosa el intelecto. El que pinta sus acciones con los sentidos externos; los interiores explica en la tabla del silencio. - «Oh, bella ninfa, (prorrumpe Minerva) este joven cuerdo, por verte de su amor causa, te hizo de su mano efecto.

El alma que te ha infundido, es lumbre del que supremo sacó el litigio que admiras del caos con poder inmenso. Débesle corresponder, con aquel conocimiento que el sujetarse a tu amor tiene de heroico sujeto. Tu nombre será Pandora que don de todos en Griego denota, porque de todos eres el don más perfecto. Dante el vegetar las plantas, los brutos el sentimiento, los ángeles la razón, las estrellas el imperio: $Y$ este que te hizo su imagen, el albedrío, inquiriendo que solo tu beldad grande iguala a su grande afecto. Celoso Júpiter brama 
porque deste joven tierno tomas la luz en tus ojos, y la afición en tu pecho De la envidia te asegura darte yo en tu amante atento el laurel contra sus rayos, contra sus sierpes el fresno. Los elementos con ser tan contrarios; en sus centros por defenderte se juntan, pacíficamente opuestos. De castillos coronada la Tierra, expuesta a tus fueros tiene diferentes minas,

y muchas bocas de fuego.

Sirvela de foso el Mar, que espín de cristal inquieto, tira saetas de espuma acometido del viento.

De sus llaves te hace guarda el adivino Proteo, para que cierres las puertas que son de tus Argos puertos. Debajo de tu bandera hacen alarde guerrero, con sus verdes campos Flora, con sus dos infantes Venus.

Eolo es el capitán

de los caballos ligeros,

que al rededor de la Tierra van el caracol haciendo.

Por el campo turquesado toma el aire los pertrechos aduar de cuantas tiendas forman nebulosos lienzos. Plaza de lucientes armas el encendido elemento con tonante artillería arroja balas de fuego Las esféricas ciudades se fortifican, teniendo por murallas a los dioses, y a las estrellas por pueblo. Torres levanta advertido tu amante en su asalto fiero, con más dicha que Nembrot, con más razón que Tifeo. Tan en vano se resiste Júpiter, tu fuerza viendo, que te juzga su Tarquina, creyéndose tu Lucrecio. Entre los Dioses desciende con verdes ramos, pidiendo la paz que busca en tus ojos, hallando la guerra en ellos. No la prevención te falte, aunque se muestra sereno: que más cauteloso engaña 
el mar, cuando está más quieto.

Sube al trono con tu amante,

para que el blando himeneo

baje a uniros con las teas

que enciende el vendado Teos».

Dijo: y echando los brazos

a la dama el galán tierno,

en zodiaco florido

hace un géminis venéreo.

Tálamo y dosel les forman

con fragancias, y gorjeos

en el Cáucaso las flores,

los pájaros en el viento.

Por los cielos y la tierra

celebran su casamiento

la noche con luminarias,

y con mudanzas el tiempo.

Cuerdas de cristal los ríos

en la guitarra del suelo,

suenan tocadas del Aura,

que mueve frondosos dedos.

Baila gallarda la Aurora,

sacando al rubio Timbreo:

y las harmónicas aves

de ramo en ramo el salterio.

A su Flora rodeando

hace Favonio el torneo,

saliendo con el las flores

al son de sus instrumentos.

Mueve las plantas con frutas

que llevan a este himeneo

las náyades en sus fuentes,

la diosa chipria en sus cestos.

Mesa el éter de los dioses,

en sus sillas no están quedos,

con el raro orden, que todo

a mediodía anda a ruedo.

Por su cabecera corre

el primer raptor, cubriendo

al que amigo de dos caras

se muestra en sus hemisferios.

Con brindis de agua saluda

el segundo un vidrio hecho

a las mozas que por el

danzan en el firmamento.

Con sus sesenta figuras

da vueltas el azul viejo que siendo capón de leche, empolló en el mar a Venus. Con pies de plomo, el canario hace el patricida hambriento

que por rey de Acuario ungido, la capona enseñó al cielo.

Júpiter toca las vacas,

en figura de becerro

que formaron por su mal

los perilos del hebreo.

Trae una danza de espadas 
aquel rojo pendenciero

que fue con Venus un macho,

y con Adonis un puerco.

Nunca hacer la temeraria

le deja el claro mancebo

que con manos de luz toca

la lira del universo.

Crepusculea el planeta

que hace danzar con culeros,

en cuanta conjunción magna

toma papel de tercero.

El correo de los dioses,

canta según sus aspectos,

sin templar la gaita al malo,

ni dar en la tecla al bueno.

Baila morisca la luna

con el ondeado pelo

que Apolo saca a las claras,

y a las marinas Nereo.

Con mal pie el dios de la fragua

se derrienga en el festejo

que limpiándose los mocos,

va reverencias haciendo.

Juno, diosa de las bodas

tañe airosa su pandero,

con la ninfa que en el aire,

es la c de los requiebros.

Tetis danza fríamente

con el Bóreas, porque fiero

robando a la hermosa Oritia,

da con sus aguas en seco.

Toca el castrador Cibeles,

pinos como niña haciendo,

mojigangas de piñones,

aunque castrados derechos.

Salen las damas de Cintia

con la noche que de medio

ojo tapada, a la boda

viene cubierta de negro.

Dale tal susto a la novia,

que acostándose en el lecho,

por persuasión de su esposo,

no cena más que unos huevos.

Jove a lo lechuzo apaga

el candil de sus contentos,

por la que con el torcida

le da la luz de los celos.

La Melisendra se espanta,

a las ancas que el Gaiferos

la echa, con el cansancio

que pone en prisa al resuello.

Hecho un águila el dios ígneo

se lo lleva por los vientos

con las uñas, que de asco

le hace echar las tripas luego.

Grita atormentado el mozo,

a la oreja de los pueblos

que Jove vuelve en narcisos, 
porque aborrezcan sus ecos.

Llueven plagas a Pandora,

por amar a Prometeo,

no dejándolo salir

del Egipto de su pecho.

Contra el poderoso amante

busca a sus ansias remedio,

Semíramis en ardides,

Penélope en galanteos.

Muda el nombre en el de Asun,

que significa en hebreo

fuerte, porque en todo fuerte

resiste asaltos obscenos.

Socórrela el bravo héroe

que por vengar a su muerto

padre, dejaba en Sicilia

hecho un volcán a Tifeo.

Va contra el águila o buitre,

que al pie de un monte soberbio martiriza al que en su cumbre

supo las cosas del Cielo.

Con la flecha que da el éter,

hiere el pájaro sangriento,

y libra por su valor

al que toma por maestro.

Enséñale agradecido

el orden de los luceros

que en los ojos de Pandora

vuelven a ser sus espejos.

La matrona alborozada

con su amado Prometeo,

está como digan dueñas,

en los brazos de sus dueños.

Denomina al Asia, donde

este nombre consiguiendo,

dio con su constante amor

al galán de Europa celos. 